\title{
Petrophysical Characterizations of Shale Gas Reservoirs of the Ranikot Formation in the Lower Indus Basin, Pakistan
}

\author{
Kazunori Abe ${ }^{\mathrm{a}, *}$, Nouman Zobby ${ }^{\mathrm{b}}$, Hikari Fujii ${ }^{\mathrm{c}}$ \\ aDepartment of Earth Resource Engineering and Environmental Science, Faculty of International Resource Sciences, Akita University. \\ Email: abe@mine.akita-u.ac.jp \\ ${ }^{b}$ Department of Petroleum and Gas Engineering, Faculty of Engineering and Architecture, Baluchistan University of Information \\ Technology Engineering and Management Sciences. Email: nauman.zobby@buitms.edu.pk \\ 'Department of Earth Resource Engineering and Environmental Science, Faculty of International Resource Sciences, Akita University. \\ Email:fujii@mine.akita-u.ac.jp
}

\begin{abstract}
The complex pore structure with nano-pores of shale gas reservoirs has an impact on the hydrocarbon storage and transport systems. We examined the pore structure of the shales of the Ranikot Formation in the Lower Indus Basin, Pakistan to investigate the full scaled pore size distributions by using a combination of techniques, mercury injection capillary pressure analysis and low pressure gas adsorption methods using $\mathrm{N}_{2}$ and $\mathrm{CO}_{2}$. Isotherm curves obtained $\mathrm{N}_{2}$ and $\mathrm{CO}_{2}$ adsorptions were interpreted using density functional theory analysis for describing the nano-scaled pore size distributions. The pore geometry of the shales was estimated to be slit-type from the isotherm hysteresis loop shape. The pore size distributions determined the density functional theory showed the dominant pore size of below around $10 \mathrm{~nm}$. The Micro-scale effects such as slippage and adsorption/desorption also significantly influence the gas flow in nano-pore structure. The gas flow regimes in shales are classified into four types Darcy flow, slip flow, transition flow, Knudsen flow based on the value of the Knudsen number. Applying the specific reservoir conditions in Ranikot shale and pore size distribution to the Knudsen number, the gas flow regimes of the Ranikot shales were estimated mostly within the transition and slip flow.
\end{abstract}

Keywords: Knudsen number; petrophysical characterization; shale gas; pore structure; Ranikot formation

\section{Introduction}

Shale gas has become an increasingly important source of natural gas in the world and has been perceived as a potenial source of energy supplyment for decades. Shale is fine-grained clastic sedimentary rocks composed of clay minerals and a trace amount of fragments of quartz, feldspar and calcite. Shale rock is one of potential petroleum source rock The shale gas is natural gas trapped within shale formations, which consists of a large amount of lithified clays with organic material and detrital minerals. The organic matter is an integral constituent for a productive shale gas reservoir.

Recently in Pakistan, the Advanced Resources International Inc. estimated a total risked shale gas in-place of 586 trillion cubic feet (TCF) and the risked technically recoverable of 105 TCF [1]. The Ranikot Formations in the Lower Indus Basin in Pakistan is one of the potential source

*Corresponding author. Tel.: +81-18-889-3079

1-1 Tegata gakuen-machi, Akita, Akita, Japan, 010-8502 rock with a total organic carbon of about $2.0 \%$ for gasproducing. The Ranikot Formation is 26,780 square miles, thickness of formation ranging from 1,000 to 3,000 feet with a net shale thickness of about 200 feet. The risked of Ranikot shale formation has shale gas in-place of 55 TCF [1]. However, the detailed petrophysical characterizations of the Ranikot shales formations have not been still conducted due to limited assets and techniques in the last decayed.

Characteristics of pore structure with nano-pores in shales was to elucidate the formation of a gas storage and gas flow in shale gas. Fluid invasion methods that have typically been used for pore structure to analyze characteristics of shale including a combination of mercury injection capillary pressure (MICP) and a low-pressure gas adsorption methods (LPA) [2-4]. MICP method is useful for characterizing mesopore (pore size in diameters between 2 $\mathrm{nm}$ and $50 \mathrm{~nm}$ ) and macropore (pore size in diameters more than $50 \mathrm{~nm}$ ), however, the pore structures are distortion in the pore size limit around $4 \mathrm{~nm}$ regarding to compressibility effects. On the other hand, LPA method using $\mathrm{N}_{2}$ or $\mathrm{CO}_{2}$ are commonly used to analyze the characteristics of the pore 
structure $<2 \mathrm{~nm}$ of pore size in diameter. Previous studies of pore structures in shale rocks from unconventional gas reservoirs have focused on Density Functional Theory (DFT) that DFT theory is used to interpret the potential source rocks technique by modern statistical thermodynamics [5] such as estimation of kerogen in the Barnett shales [6]. A rigorous methodology for characterizing pore structures and flow properties of tight gas sands was provided by Rushing et al. based on a rocktyping procedure [7].

The pore structures with nano-pores in shales have low permeability (nano-darcy) and transport systems acting at different scales; (1) surface diffusion of molecules adsorbed to kerogen and clay, (2) Knudsen diffusion and slip flow in micropore, mesopores, and lower macropores, (3) Darcy flow in macropores [8]. The gas flow regimes in shales are classified into four types such as Darcy flow, slip flow, transition flow, Knudsen flow by using the value of the Knudsen number [9]. Micro-scale effects such as slippage and adsorption/desorption also significantly influence the gas flow in nanopore structure. Therefore, the analysis of micropore structure can provide a better understanding of the gas storage and migration pathways in shale rock. Efficient depiction of the nanopore structure is critical for the quantification of producible resources and the evaluation of long term production behavior [4].

The aims of this research were to elucidate the characteristics of pore structures with nano-pores in the Ranikot shale formation to understand gas storage and gas flow by LPA and MICP methods on the basis of the Knudsen number.

\section{Experimental Methods}

\subsection{Materials}

The shale samples were collected from four area in the Ranikot Formations in the Lower Indus Basin, Pakistan. These shale sample were collected in different depth in each area such as 1,945-2,070 m from Dhodak area, 1,125-1,250 $\mathrm{m}$ from Bobi area, 1,190-1,290 m from Kadanwari and 485$838 \mathrm{~m}$ from Daru area. The shale samples were dried at temperature $333 \mathrm{~K}$ for 24 hours to expel solution such as water.

\subsection{Low pressure gas adsorption methods (LPA)}

Physisorption filling may be regarded as the primary physisorption process at the micropore scale and surface coverage takes place on the walls of mesopores or open macro-pores, which causes mono-multilayer adsorption and pore condensation [10]. LPA method is a well-established approach for the characterization of pore structures in shale. The shale rocks samples were treated in different temperature regarding to the LPA method using $\mathrm{N}_{2}$ and $\mathrm{CO}_{2}$ isotherm. In case of the LPA method using $\mathrm{N}_{2}$ isotherm, the shale samples were treated at temperature of $77 \mathrm{~K}$. On the other hand, the LPA method using $\mathrm{CO}_{2}$ isotherm was treated the shale samples at temperature of $273 \mathrm{~K}$. The analysis is

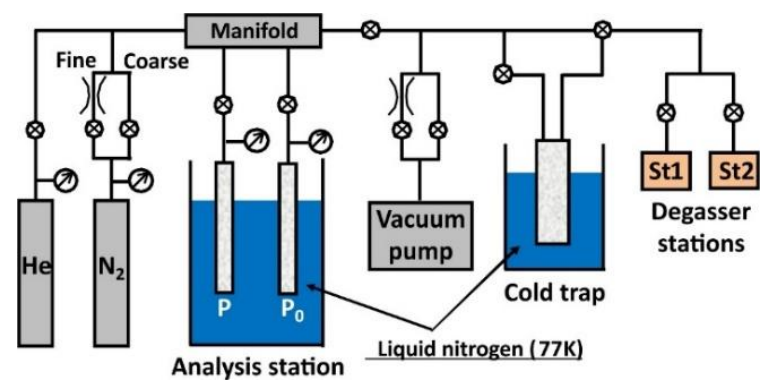

Figure 1. Schematic diagram of LPA using $\mathrm{N}_{2}$

performed the Autosorb iQ (Quantachrome Instruments), which the schematic diagram of the LPA method using $\mathrm{N}_{2}$ is shown in Fig. 1. The samples were pre-dried and outgassed under a vacuum at temperature of $333 \mathrm{~K}$ for 3 hours. The nitrogen molecules were expelled water molecules and trace gas in micropores to degas and remove moisture contents before pore structure analysis. The isotherms are used to quantify the amount of gas adsorbed at relative pressure $\left(\mathrm{P} / \mathrm{P}_{0}\right)$, where $\mathrm{P}$ is the absolute equilibrium pressure and $\mathrm{P}_{0}$ is the saturated vapor pressure of each gas at laboratory conditions. $\mathrm{N}_{2}$ adsorption via the physisorption filling of wide micropores still occurs at very low pressures. The pores with the minimum diameter of $1.3 \mathrm{~nm}$ can be explored by $\mathrm{N}_{2}$ adsorption at $77 \mathrm{~K}$. On the other hand, the relatively high boiling point $(273 \mathrm{~K})$ and high saturation vapor pressure (up to $3.5 \mathrm{MPa}$ ) of $\mathrm{CO}_{2}$ make studying its adsorption at $273 \mathrm{~K}$ an acceptable method for investigating materials with very narrow micropores (about $0.33 \mathrm{~nm}$ ) [2]. The maximum $\mathrm{P} / \mathrm{P}_{0}$ with $\mathrm{CO}_{2}$ at $273 \mathrm{~K}$ is 0.03 (corresponding to ambient pressure). $\mathrm{CO}_{2}$ adsorption can be found the maximum pore diameter of $2 \mathrm{~nm}$. In this study, the DFT model was used for the PSD determination of shale samples included micropores through to lower macropores.

\subsection{Mercury injection capillary pressure analysis (MICP)}

MICP provides a wide range of information such as PSDs, total pore volume, bulk density and specific surface area [2]. The grain size of the shale samples is around $5 \mathrm{~mm}$, and its sample weight are at least 0.4 gram. The mercury intrusion pressure values are converted to the pore size by using the Washburn equation [11]. The contact angle and mercury surface tension used in the Washburn equation for pore size calculations were $141^{\circ}$ and $480(\mathrm{mN} / \mathrm{m})$, respectively. The MICP measurement was accomplished in a Thermo Electron Corporations porosimeter that attained a maximum instrusion pressure of $400 \mathrm{MPa}$. In this study, the pressures used for instruction were up to $200 \mathrm{MPa}$.

\subsection{Flow regimes based on the Knudsen number}

The gas flow regimes are calculated by the Knudsen number $\left(K_{n}\right)$, which is defined as Eq.(1).

$$
K_{n}=\frac{\lambda}{d_{p}}
$$


where $\lambda$ is the mean free path of a gas molecular (m), $d_{p}$ is the diameter of the pore (m), which is given by Eq.(2).

$$
\lambda=\frac{k_{B} T}{\sqrt{2} \pi p d^{2}}
$$

where $k_{B}$ is the Boltzmann constant $\left(1.38 \times 10^{-23}(\mathrm{~J} / \mathrm{K})\right), T$ is the temperature $(\mathrm{K}), p$ is the pressure $\left(\mathrm{N} / \mathrm{m}^{2}\right), d$ is the diameter of the gas molecular $(\mathrm{m})$.

For the Knudsen flow $\left(K_{n}>10\right)$, gas molecules collision frequently between gas molecular and pore wall is dominant. Therefore, the continuum assumption becomes invalid, and flow rate and pressure drop are no longer accurately predicted using Darcy's law. When $K_{n}<0.01$, the Darcy flow is a dominant in the pore because the mean free path of gas molecules is negligible relative to the pore diameter. This intermediate zone $\left(0.01<K_{n}<10\right)$ is divided into slip and transition flow regimes. For the slip flow, the effect of discontinuity appears near the pore wall, whereas fluid flow is based on the continuity far from the pore wall. The Knudsen number has an influence on the permeability of shales. For example, the permeability was underestimated than actual permeability under slip and early transition flow conditions [9]. Table 1 summarizes these four types of gas flow regimes and the driving forces [8].

\section{Results and Discussion}

Fig. 2 shows isotherm curves using $\mathrm{N}_{2}$ adsorption at 77 $\mathrm{K}$ for the Ranikot shale samples. These sampling depths of each of fields, Dhodak, Bobi, Kadanwari and Daru are around 2,070 m, 1,250 m, 1,290 m and $838 \mathrm{~m}$, respectively. The shapes of the isotherm curves suggest that the all shales contain narrow slit-like pores according to the International Union of Pure and Applied Chemistry (IUPAC) [12]. The micropores surface area and mesopores volume of Ranikot shale are domain of the pore structure. Fig. 3 shows the PSDs determined by using DFT model based on the isotherms obtained $\mathrm{N}_{2}$ adsorptions for the Ranikot shales. The plots of the $d V / d(\log D)$ versus pore diameter is used to represent the PSD. Unimodal PSD of Dhodak field sample at the depth of $2,070 \mathrm{~m}$ shows pore modes at $1.40 \mathrm{~nm}, 1.69 \mathrm{~nm}$ and 3.79 $\mathrm{nm}$. Kadanwari field sample at depth of $1,290 \mathrm{~m}$ revealed the strong pore peak at $3.79 \mathrm{~nm}$ and Bobi field sample at depth of $1,250 \mathrm{~m}$ revealed $8.53 \mathrm{~nm}$.

Table 1. Summary of flow regimes, Knudsen number, driving force [8]

\begin{tabular}{|c|c|c|}
\hline Flow regime & Knudsen number & Driving force \\
\hline Knudsen flow & $K_{n}>10$ & $\begin{array}{c}\text { Total concentration } \\
\text { gradient and molecular } \\
\text { weight }\end{array}$ \\
\hline Transition flow & $0.1<K_{n}<10$ & $\begin{array}{l}\text { Mostly Knudsen flow with } \\
\text { some Darcy flow }\end{array}$ \\
\hline Slip flow & $0.01<K_{n}<10$ & $\begin{array}{l}\text { Mostly Darcy flow with } \\
\text { some Knudsen flow }\end{array}$ \\
\hline Darcy flow & $0.01>K n$ & Total pressure gradient \\
\hline
\end{tabular}

While the Daru field sample at depth of $838 \mathrm{~m}$ shows the highest value at $3.79 \mathrm{~nm}$. The PSD determined DFT model based on $\mathrm{N}_{2}$ and $\mathrm{CO}_{2}$ isotherms indicated that the nano-pores of Dhodak field samples were characterized ranges of 0.5 $29 \mathrm{~nm}$, Kadanwari field ranges of 3-29 nm, Bobi field ranges of $0.3-10 \mathrm{~nm}$, and the Daru field ranges of $1.0-10 \mathrm{~nm}$. Furthermore, the full scaled PSDs of the Dhodak sample at the depth of 2,070 were determined by using the combination of MICP, $\mathrm{N}_{2}$ and $\mathrm{CO}_{2}$ adsorption (Fig. 4). The MICP and $\mathrm{CO}_{2}$ adsorption give more information about the macropores and ultra-micropores (pore diameters less than $2 \mathrm{~nm}$ ), respectively. The shale samples have a multi-modal distribution with the major peaks at approximately 0.57 $0.82 \mathrm{~nm}, 3.78 \mathrm{~nm}$ in the micropores and mesopores. While the PSD based on the MICP shows the wide range PSD in the macropores.
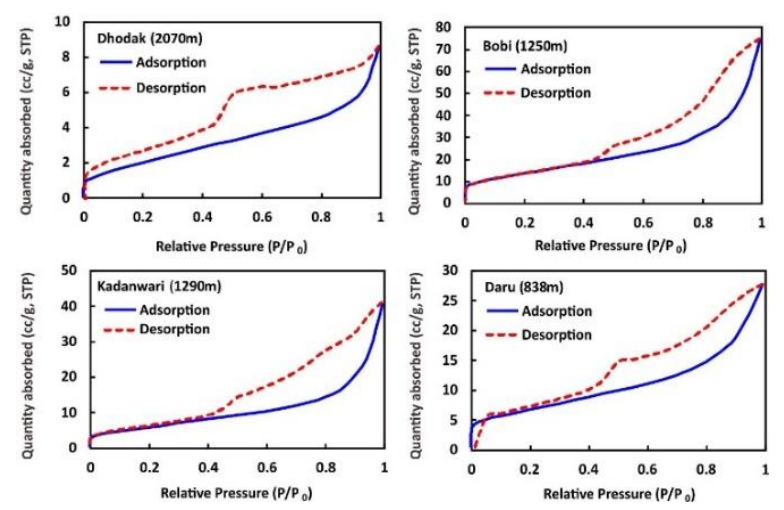

Figure 2. Adsorption and desorption isotherms of the Ranikot shales using $\mathrm{N}_{2}$ adsorption. The sampling depths in each of the fields, Dhodak, Bobi, Kadanwari and Daru are around 2070m, 1250m, 1290m and 838m, respectively
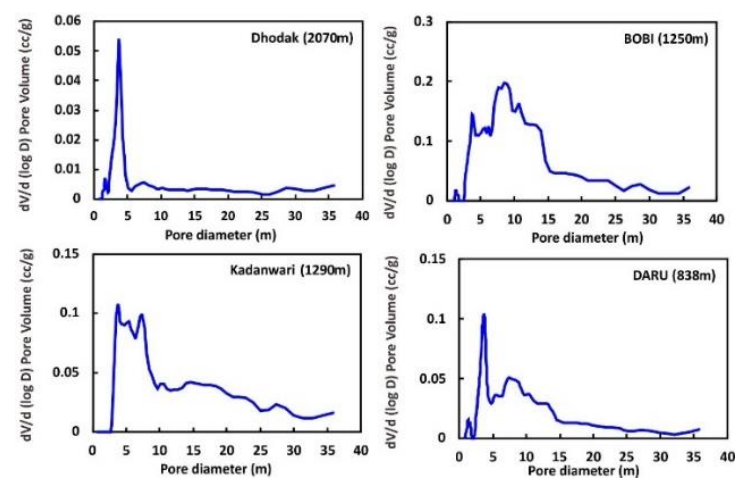

Figure 3. PSDs determined DFT analysis based on the isotherm obtained $\mathrm{N}_{2}$ adsorption for the Ranikot shales, where the sampling depths in each fields of Dhodak, Bobi, Kadanwari and Daru are around 2070 m, 1250 m, $1290 \mathrm{~m}$ and $838 \mathrm{~m}$, respectively. 


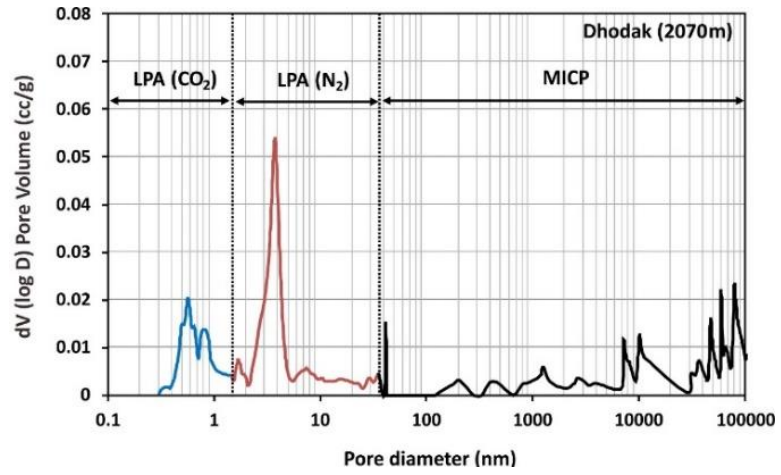

Figure 4. PSD determined by the combination of MICP, $\mathrm{N}_{2}$ and $\mathrm{CO}_{2}$ adsorption using DFT method for the Ranikot shales of Dhodak filed at the depths of $2070 \mathrm{~m}$

Figure 5 shows the estimations of the flow regimes based on the Knudsen number for the Ranikot shale in each fields of Dhodak, Bobi, Kadanwari and Dara at each of sampling depths. For the calculations of the Knudsen number, $d$ is used the molecular diameter for methane $(0.38 \mathrm{~nm})$ and the specific pressure and temperature at each of sampling depths [13]. The Dhodak and Daru shale samples exhibit the transition and slip flow mechanism, and the Kadanwari and Bobi field shale samples exhibit the Knudsen flow along with transitional and slip flow. The transportation of gas in Ranikot shale lies mostly within the transition and slip flow regimes.

\section{Conclusion}

In this work, the pore structure of the shale samples of the Ranikot Formation in the Lower Indus Basin, Pakistan have been investigated using MICP and LPA applying $\mathrm{N}_{2}$ and $\mathrm{CO}_{2}$. The pore geometry of all the shales were interpreted as narrow slit-like pores, as evidenced by shapes of the hysteresis loop according to IUPAC classification. The PSD determined DFT model based on $\mathrm{N}_{2}$ and $\mathrm{CO}_{2}$ isotherms indicated that the nano-pores of Dhodak field samples were characterized ranges of 0.5-29 nm, Kadanwari field ranges of 3-29 nm, Bobi field ranges of 0.3-10 nm, and the Daru field ranges of $1.0-10 \mathrm{~nm}$. Combined the PSD based on the MICP, the shale samples have been had multimodal wide PSDs. The flow regimes of the Ranikot shales are estimated based on the Knudsen number, applying specific temperature and pressure at the sampling depths. As a result, the Dhodak and Daru shale samples exhibit the transition and slip flow mechanism, and the Kadanwari and Bobi field shale samples exhibit the Knudsen flow along with transitional and slip flow. The gas regimes in Ranikot shales lies mostly within the transition and slip flow.
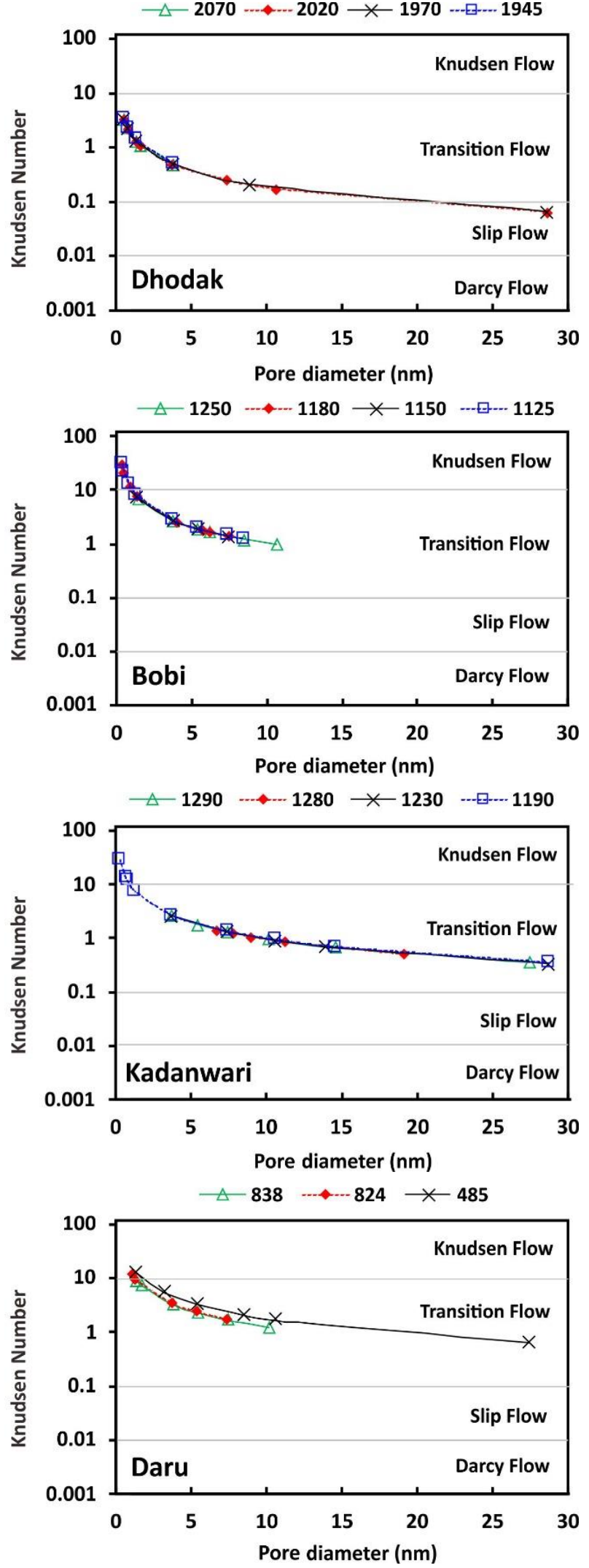

Figure 5. Estimations of the flow regimes based on the Knudsen number for the Ranikot shale in Dhodak, Bobi, Kadanwari and Daru fields at each of the sampling depths. 


\section{Acknowledgements}

The authors would like to thank Japan International Cooperation Agency for supporting this research through the project on "In Country Training and Provision of Equipment for Baluchistan University of Information Technology Engineering and Management Sciences" and express our sincere gratitude to Directorate General of Petroleum Concession of Pakistan for providing samples. This work was supported by Akita University Support for Fostering Research Project.

\section{References}

[1] U.S. Energy Information Administration, World Shale Gas and Shale Oil Resource Assessment. Technically Recoverable Shale Oil and Shale Gas Resources: India and Pakistan. 2013

[2] Matthias T, Katsumi K, Alexander VN, James PO, Francisco R-R, Jean R, Kenneth SWS. Physisorption of gases, with special reference to the evaluation of surface area and pore size distribution (IUPAC Technical Report). Pure Appl. Chem. 2015; 87 (9-10): 1051-1069.

[3] Jingqiang T, Brian H, Nicolaj M, Jinchuan Z, Christopher JB, Dorothee H, Ger VG, Bruce AT. Natural gas potential of Neoproterozoic and lower Palaeozoic marine shales in the Upper Yangtze Platform, South China: geological and organic geochemical characterization. International Geology Review. 2015; 57: 305-326.
[4] Mingming W, Li Z, Yongqiang X, Jinhua L, Ping'an P. Nanopore structure characterization for organic-rich shale using the non-localdensity functional theory by a combination of $\mathrm{N}_{2}$ and $\mathrm{CO}_{2}$ adsorption. Microporous and Mesoporous Materials. 2016: 227: 88-94.

[5] Do DD, Do HD. Pore characterization of carbonaceous materials by DFT and GCMC simulations: A Review. Adsorption Science and Technology. 2003; 21(5): 389-423.

[6] Adelola GA, I. Akkutlu, Daniel ER, Chandra SR. Characterization of Barnet Shale Pore Size Distribution using DFT Analysis and Monte Carlo Simulations. Society of Petroleum Engineers. 2011; SPE147397-MS.

[7] Jay AR, Kent EN, Thomas AB. Rock Typing - Key to understanding Productivity in Tight Gas Sands. Society of Petroleum Engineers. 2008; SPE-114164-MS

[8] Rob H, John V, Mark Z. Experimental investigation of matrix permeability of gas shales. AAPG Bulletin. 2014; 98(5): 975-995.

[9] Ali SZ, Roberto A. Knudsen's Permeability Correction for Tight Porous Media. Transport in Porous Media. 2012; 91: 1: 239-260.

[10]Daniel JKR, Robert MB. The importance of shale composition and pore structure upon gas storage potential of shale gas reservoirs. Marine and Petroleum Geology. 2009; 26(6): 916-927.

[11] Edward WW. Note on a method of determining the distribution of pore sizes in a porous material. Proceedings of the National Academy of Science. 1921; 7: 115-116.

[12] Kenneth SWS. Reporting Physisorption Data for Gas/Solid Systems with Special Reference to the Determination of Surface Area and Porosity. Pure Appl. Chem. 1985; 57: 603-619.

[13] Breck DW. Zeolite Molecular Sieves: Structure, Chemistry, and Use. Wiley. 1974; ISBN 13: 9780471099857. 